\title{
THE ROLE OF RESISTIN IN THE PROGRESSION OF NON-ALCOHOLIC FATTY LIVER DISEASE
}

\author{
Zhuravlyova L.V., Elhaj O.V. \\ Kharkiv National Medical University, Ukraine \\ https://doi.org/10.35339/ic.8.3.157-162
}

\begin{abstract}
The aim of the research was to study the relationship between plasma concentrations of resistin and indicators of enzyme and pigment metabolism in patients with non-alcoholic fatty liver disease (NAFLD) and its combination with type 2 diabetes mellitus (DM-2) depending on phenotype of patients. Materials and methods. On the base of Kharkiv Regional Hospital a total of 90 patients were examined, including patients with NAFLD $(n=20)$ and its combination with DM-2 with normal body weight $(\mathrm{n}=20)$ and obesity $(\mathrm{n}=50)$, as well as 20 healthy volunteers. A complex of clinical, laboratory and instrumental (including liver biopsy in 9 patients) examinations of patients was performed. Results. A direct relationship was established between the level of resistin and indicators of enzyme and pigment exchange in groups of patients with combined pathology. A significant increase of resistin plasma level, as well as disorders of the liver function were determined in all groups of patients in comparison with the controls. The most marked changes were revealed in patients with combination of NAFLD, DM-2 and obesity. Conclusions. The established relationship between the level of resistin and the indicators of the liver functional state suggests that an increase of resistin level may reflect the presence of impaired liver function in patients with NAFLD in combination with DM-2, predicting the progression of NAFLD. In order to detect the disorders of liver function in patients with DM-2, it is recommended to determine the level of resistin in patients with NAFLD, especially when concomitant obesity is present. The higher the body mass index in obese patients, the more pronounced the effect of resistin on liver function in patients with this comorbid pathology.
\end{abstract}

Keywords: non-alcoholic fatty liver disease, type 2 diabetes, obesity, resistin.

\section{Introduction}

Non-alcoholic fatty liver disease (NAFLD) is characterized by the presence of fatty liver infiltration, verified by visual tests or histology in the absence of alcohol abuse $(<40$ grams of pure ethanol per day for men and 20 grams for women), the use of steatogenic drugs, or hereditary diseases [1,2]. NAFLD is associated with obesity and insulin resistance (IR) [3].

The issues of etiopathogenesis of this metabolic pathology still remain unresolved.

Adipose tissue is a key endocrine organ that communicates with brain, muscle, liver, and pancreas, thereby maintaining energy homeostasis. The communication between adipose tissue and

Corresponding Author:

Olena Elhaj MD, PhD, Associate Professor,

Department of Internal Medicine No.3

and Endocrinology, Kharkiv National

Medical University, Ukraine.

E-mail: ognevaelena84@gmail.com other organs is mainly mediated by multiple endocrine substances secreted by adipose tissue, referred to as "adipocytokines" [4-8]. Adipose tissue hormones, for example, resistin, is considered in the literature as a pathogenic factor for the development of obesity and IR, it functions as a signal to reduce insulin-stimulated glucose uptake [9-14], and is also referred to as "intrahepatic cytokine" [15-17], which affects on function and creates a pro-inflammatory effect in the stellate cells of the liver, key modulators of fibrosis.

The search for common mechanisms between the development of NAFLD and metabolic disorders will reveal additional ways of preventing and diagnosing this comorbid pathology, therefore, requires additional study.

2. Purpose, subjects and methods:

2.1. The purpose of the research was to study the relationship between plasma concentrations of resistin and indicators of enzyme and pigment metabolism in patients with non-alcoholic fatty 
liver disease (NAFLD) and its combination with type 2 diabetes mellitus (DM-2) depending of phenotype of patients.

\subsection{Subjects \& Methods}

On the base of Kharkiv Regional Hospital a total of 90 patients were examined. Of these, patients with NAFLD (group 1; $\mathrm{n}=20$ ) and its combination with DM-2 with normal body weight (group 2; $\mathrm{n}=20$ ) and obesity (group 3; $\mathrm{n}=50$ ), as well as 20 healthy volunteers (control group).

Verification of diagnoses was carried out according to the ICD-10 and WHO classifications. In all patients, the parameters of the functional state of the liver, body mass index (BMI) were determined.

The diagnosis of diabetes was verified by biochemical testing, which made it possible to assess the state of carbohydrate metabolism using standard generally accepted methods.

According to the Quetelet index, normal body weight was established with a BMI of 18.5 to $24.9 \mathrm{~kg} / \mathrm{m} 2$, the diagnosis of "obesity" was made in patients with a BMI ? $30 \mathrm{~kg} / \mathrm{m} 2$.

The diagnosis of NAFLD was verified by the results of a complex clinical and laboratory, biochemical (using reagent kits "DacSpectroMed" (Moldova)) and instrumental (ultrasound examination of the liver) examination in accordance with the standards of examination of patients with gastroenterological diseases. The resistin level was determined by the enzyme-linked immuneassay using the BioVendor reagent kit (Czech Republic).

To clarify the nature and degree of liver damage, selective puncture biopsy (PB) of the liver was performed, followed by morphological examination of biopsies in 9 patients. All examined patients had no previous viral hepatitis, alcoholism was excluded.

Statistical processing of research results was carried out using analysis of variance and correlation (BIOSTAT version 4.03 and Statistica version 6.1 software packages). Student's t-criteria was used in independent groups, taking into account the difference in the number of observations.

All patients gave informed consent to the interviews and all types of testing.

\section{Results \& Discussion}

\section{Results}

In one of our studies, we have already provided some data on the study of resistin and its relationship with indicators of the functional state of the liver [18]. In this article, we additionally present data on the correlations between resistin and BMI in patients in order to demonstrate the dependence of this indicator on the phenotype of patients.

With regard to the investigation, the plasma levels of resistin in groups 1,2 and 3 were significantly higher than those in control group $(\mathrm{p}<0.001)$. Indicators of resistin in groups 2 and 3 were both significantly higher than those in group 1 ( $\mathrm{p}<0.001$ both), Table.

The fact that the studied parameters were increased in group 1 (patients with NAFLD without DM-2) indicates NAFLD as an independent factor for the endocrine dysfunction of adipose tissue.

We investigated indices of pigment and enzymatic metabolism as biochemical markers of liver function state.

Resistin balance $(M \pm m)$ in NAFLD patients with normal body weight and obesity

\begin{tabular}{|l|l|}
\hline \multicolumn{1}{|c|}{ Group } & Resistin level $\mathrm{ng} / \mathrm{ml}$ \\
\hline $\begin{array}{l}\text { Control group } \\
\mathrm{n}=20\end{array}$ & $4.87 \pm 0.11$ \\
\hline group 1 & \\
NAFLD & \\
$\mathrm{n}=20$ & $7.56 \pm 0.21^{*}$ \\
\hline $\begin{array}{l}\text { group 2 } \\
\text { NAFLD, DM+2 with normal body mass } \\
\text { n=20 }\end{array}$ & $8.06 \pm 0.23^{*}$ \\
\hline $\begin{array}{l}\text { group 3 } \\
\text { NAFLD, DM+2 and obesity } \\
n=50\end{array}$ & \\
\hline
\end{tabular}

Note:

$*-\mathrm{p}<0.001$ when compared with the control group;

$* *-p<0.001$ when compared with the indicators of group 1 . 
Analysis of the state of enzyme metabolism showed that serum ALT (mmol/l/g) was significantly increased in patients of groups $2(0.81$ $\pm 0.01)$ and $3(0.86 \pm 0.01)$ compared with control $(0.46 \pm 0.01 ; p<0.05)$, indicators of $1(0.60 \pm$ $0.01)$ group $(\mathrm{p}<0.05)$. Significantly higher values of serum ACT $(\mathrm{mmol} / \mathrm{l} / \mathrm{g})$ in patients of groups 2 and $3(0.67 \pm 0.01 ; 0.73 \pm 0.01 ; \mathrm{p}<0.05$, respectively) were found in comparison with the indicators of group 1 and the control group patients $(0.79 \pm 0.01 ; 0.41 \pm 0.01 ; p<0.05$, respectively). There was a significant decrease in the ratio of AST / ALT in the serum of patients in groups 2 and $3(0.76 \pm 0.01 ; 0.73 \pm 0.01 ; \mathrm{p}<0.05$, respectively) compared with patients of group 1 and control group $(0.79 \pm 0.02 ; 0.98 \pm 0.01$; $\mathrm{p}<0.05$, respectively). There was a significant increase in ALP (U/L) in the serum of patients of groups 2 and $3(4.79 \pm 0.11 ; 6.50 \pm 0.079$; $\mathrm{p}<0.05$, respectively) compared with patients of group 1 and the control group $(3.45 \pm 0.11 ; 1.72$ $\pm 0.06 ; \mathrm{p}<0.05$, respectively).

There was a significant increase in total bilirubin in the serum $(? \mathrm{~mol} / \mathrm{l})$ in patients of groups 2 and $3(14.19 \pm 0.20 ; 16.12 \pm 0.09 ; \mathrm{p}<0.05$, respectively) compared with indicators of patients of group 1 and control group $(12.5 \pm 0.18 ; 10.37$ \pm 0.15 ; $p<0.05$, respectively), as well as a significant increase in conjugated serum bilirubin $(\mu \mathrm{mol} / 1)$ in patients of groups 2 and $3(6.05 \pm 0.17$; $7.94 \pm 0.1 ; \mathrm{p}<0.05$, respectively) compared with patients of group 1 and control group $(5.75 \pm 0.18$; $2.47 \pm 0.09 ; \mathrm{p}<0.05$, respectively).

It is important to note that all the above indicators of enzyme and pigment metabolism in patients of group 3 (comorbid pathology with obesity) significantly ( $<0.05)$ increased when compared with patients in group 2 (comorbid pathology with normal body weight).

Evaluating the indicators of pigment and enzymatic metabolism, in addition to the detected significant $(\mathrm{p}<0.001)$ increase in all indicators reflecting these types of metabolism (except for AST/ALT, where a significant decrease was observed), a significant impairment of these indicators was revealed in group 3 in comparison with groups 1 and 2, the reliability was not revealed between the ALT and total bilirubin values in group 1 (NAFLD) in comparison with group 2 (NAFLD and DM-2 with normal body weight).

The correlations between resistin and some indicators of enzyme and pigment metabolism in patients, mainly in the group 3, were detected.

The correlations between resistin and AST/ALT were investigated $(\mathrm{r}=-0.32, \mathrm{p}<0.05$ in group 2 ; $\mathrm{r}=-0.39, \mathrm{p}<0.05$ in group 3$)$, ACT $(\mathrm{r}=0.57, \mathrm{p}<0.05$ in group 3), ALT ( $\mathrm{r}=0.49 \mathrm{p}<0.05$ in group 3$)$, total bilirubin $(\mathrm{r}=0.59, \mathrm{p}<0.05$ in group 3$)$, conjugated bilirubin $(\mathrm{r}=0.46, \mathrm{p}<0.05$ in group 2 ; $\mathrm{r}=0.71, \mathrm{p}<0.05$ in group 3 ) and alkaline phosphatase $(\mathrm{r}=0.82, \mathrm{p}<0.05$ in group 3$)$.

Correlation links between these indicators were present and were significant mainly in group 3 . In other groups, these relationships had the same direction, but were weak.

Also, resistin was directly related to BMI in all groups of patients. Resistin was associated with BMI $(\mathrm{r}=0.83, \mathrm{p}<0.05$ in group $1 ; \mathrm{r}=0.36$, $\mathrm{p}<0.05$ in group $2 ; \mathrm{r}=0.84, \mathrm{p}<0.05$ in group 3 ).

The study implied a puncture biopsy of the liver with subsequent histological evaluation of biopsies for 9 examined patients [18], namely, two patients of group 1, three patients of group 2 and four patients of group 3 .

The "gold standard" for the diagnosis of NAFLD is a liver biopsy. However this procedure is invasive and potentially associated with complications. In selected group of patients liver biopsy was performed. Assessment of the structure of fibrotic changes showed such signs as small and large droplet steatosis, mixed fibrosis with mono- and multilobular spread with moderately pronounced signs of parenchymal and stromal reactions.

Group 1 patients (patients with NAFLD without DM-2) were found to have large-droplet fatty degeneration of single hepatocytes, as well as diffuse large-small-droplet fatty degeneration of hepatocytes with some predominance of the process in its central parts, large-droplet fatty degeneration of single hepatocytes (Fig. 1, 2).

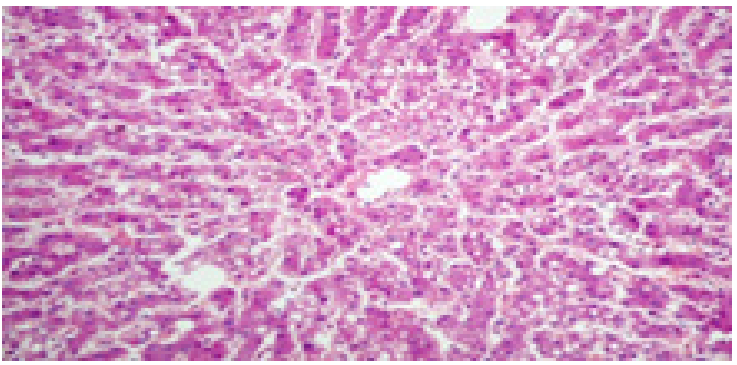

Fig. 1. Diffuse large-droplet fatty degeneration of the hepatic lobule with some predominance of the process in its central parts.

Hematoxylin and eosin, $\times 200$

Besides, ultrasound examination revealed hyperechoic liver tissue, due to diffuse fatty infiltration with a coarse-grained structure.

In group 2 patients with NAFLD in combination with DM-2 and normal body weight, attention was drawn to the presence of "hollow" 


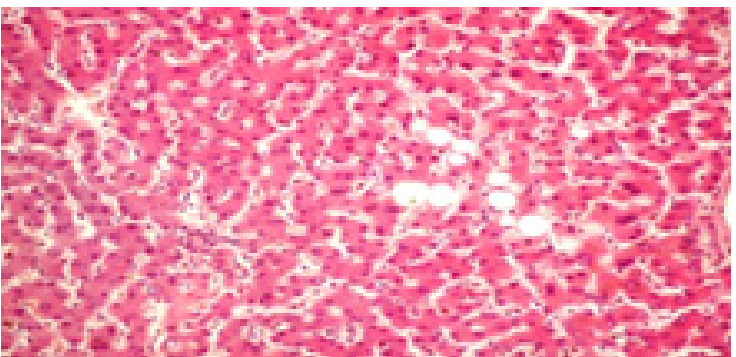

Fig. 2. Large-droplet fatty degeneration of separate hepatocytes. In separate hepatocytes, large "hollow" nuclei are detected.

Hematoxylin and eosin, $\times 200$

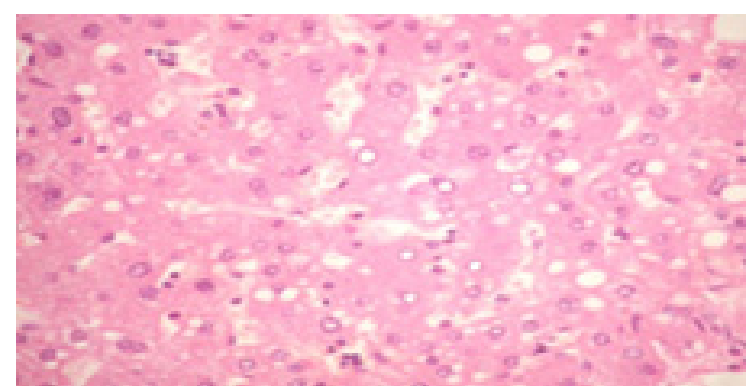

Figure 3. "Hollow" nucleus of hepatocytes against the background of hepatosis.

Hematoxylin and eosin, $\times 400$

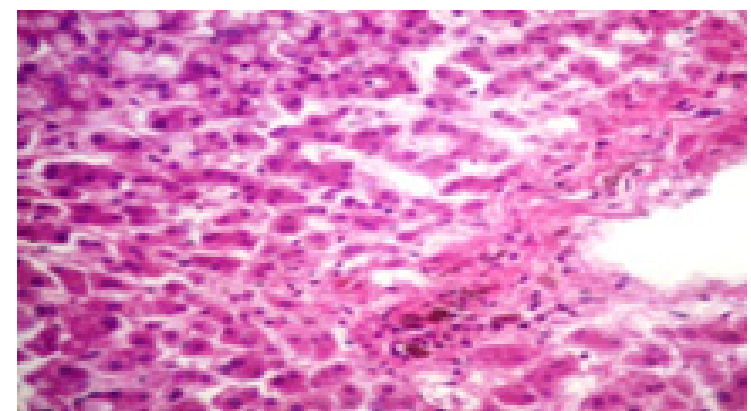

Figure 4. Small-large-droplet fatty degeneration of periportal hepatocytes. The bile ducts of portal tracts are full of bile. Hematoxylin and eosin, $\times 400$

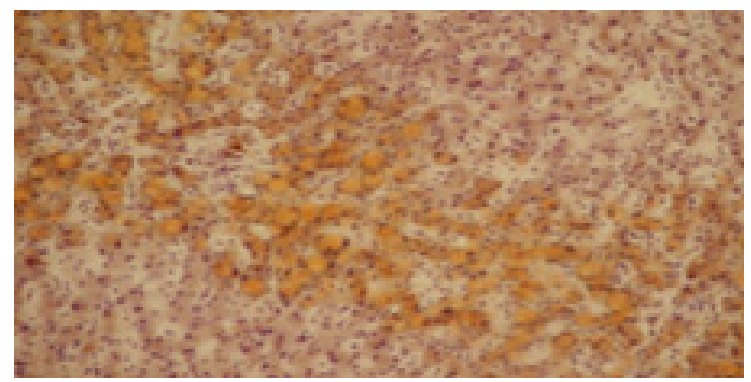

Figure 5. Sudanophil granules in the cytoplasm of hepatocytes. Sudan 3 on fat, $\times 200$

nuclei of hepatocytes against the background of hepatosis (Fig. 3), as well as bile overcrowding of the bile capillaries (a sign of steatohepatitis),

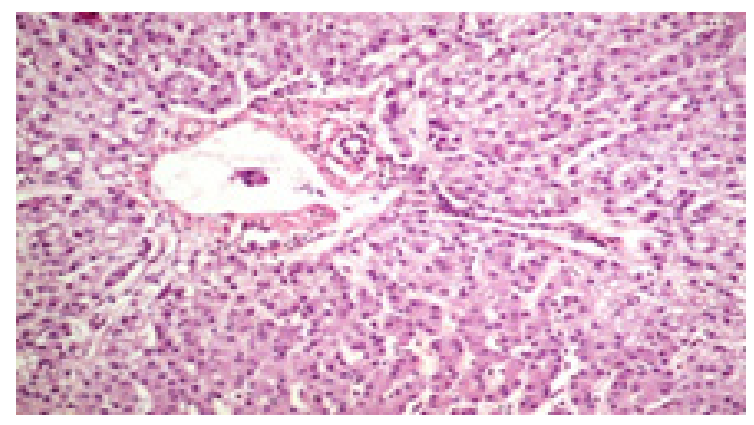

Figure 6. Focal large-droplet fatty degeneration of hepatocytes of the periporal zones.

Hematoxylin and eosin, $\times 200$

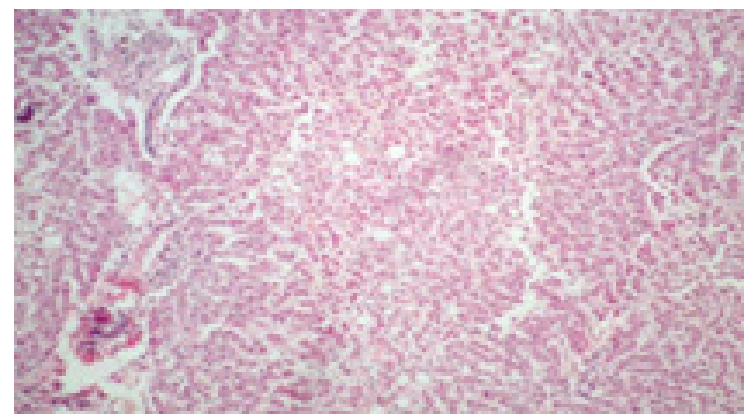

Figure 7. Focal large-small- droplet fatty degeneration of hepatocytes mainly of the central parts of the hepatic lobules. Portal tracts are significantly sclerosed with the presence of diffuse lymphohistiocytic infiltration. Hematoxylin and eosin, $\times 100$

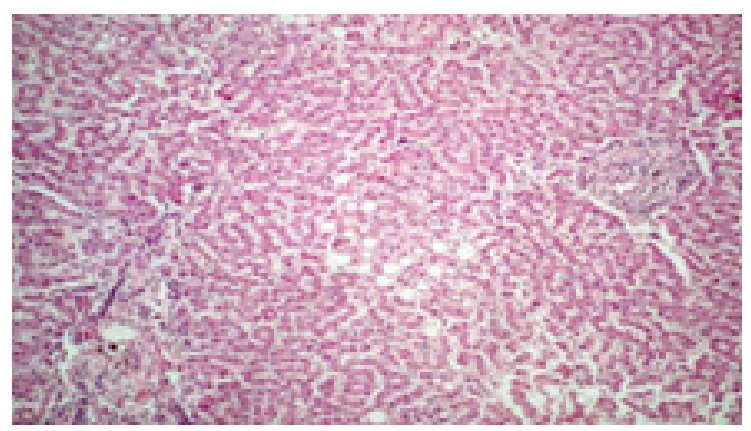

Figure 8. Sclerosis of the portal tracts with marked lymphohistiocyte infiltration against the background of focal steatosis.

Hypertrophy of the walls of the hepatic arteries with some narrowing of their lumen.

Hematoxylin and eosin, $\times 100$

(Fig. 4) and sudanophilic granules in the cytoplasm of hepatocytes (Fig. 5).

In group 3 patients (NAFLD in combination with DM-2 and obesity), there was a picture of focal coarse fatty degeneration of hepatocytes in the periportal zones (Fig. 6). The study showed signs of focal large-small-droplet fatty degeneration of hepatocytes, predominantly of the central parts of the hepatic lobules, the portal 


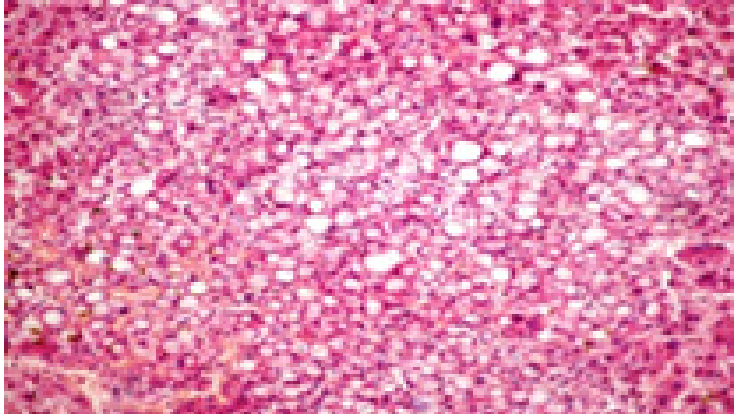

Figure 9. Large-droplet fatty degeneration of hepatocytes. Focal plethora of the hepatic parenchyma against the background of complete disorganization of its beam structure.

Hematoxylin and eosin, $\times 200$

tracts were significantly sclerosed with diffuse lymphohistiocytic infiltration, in particular against the background of focal steatosis - signs of liver fibrosis (Fig. 7, 8). Focal plethora of the hepatic parenchyma was observed against the background of complete disorganization of its beam structure - a sign of steatohepatitis (Fig. 9).

We appreciate that it is not possible to make a statistically significant conclusions concerning typical pathomorphological changes in liver tissue due to limited number of subjects involved in morphological study. However, analyzing the histological changes of biopsies of 9 examined patients, we noticed that severe inflammatory and fibrotic changes were as typical findings for patients with comorbid pathology (group 2 and group 3). The most progressive changes revealed liver biopsy results in patients of group 3, that demonstrates that obesity is an additional factor of NAFLD progression and it can become a promising vector for further research.

\section{Discussion}

Increased activity of AST and ALT in the blood serum and decreased AST/ALT ratio, indicates the development of cytolysis syndrome in the examined patients.

The tendency to an increase in bilirubin and excretory enzyme ALP confirms the development of cholestasis syndrome with impaired biliary function of the liver with impaired formation of bile micelles and damage to small bile ducts.

Increased biochemical markers of liver tissue damage against the background of IR indicates the presence of structural and functional changes in hepatocytes with the development of cytolysis and cholestasis syndromes, developing in patients with NAFLD and in comorbid pathology.

Monitoring the state of these types of metabolism has prognostic significance for diagnosing of the state of the liver in patients with
NAFLD and with its combination of DM-2, especially in the presence of obesity.

Increased level of resistin mainly in groups of the patients with comorbid pathology demonstrates the relationship of metabolic, hormonal changes and functional disorders of the liver in patients with NAFLD and DM-2, which is significantly increased in obesity. Resistin indices were significantly increased in group 1 with NAFLD without DM-2, demonstrating that NAFLD is an independent factor for disorders of the endocrine function of adipose tissue, which are significantly compounded by disorders of carbohydrate metabolism and obesity.

It is important to note that the correlation between all indicators increased and was significant in all cases in group 3 , which confirms the fact that obesity is a leading etiological factor in the pathogenesis of molecular cellular mechanisms of interaction of immune and metabolic processes in patients with NAFLD and DM-2.

In a previous scientific article, we have already suggested the relationship between resistance levels and markers of cytolysis and cholestasis [18].

We would like to focus on the pronounced relationship between the level of resistin and BMI in patients. Interestingly, the correlations between these parameters were significant in all groups, but the strongest one was found in the group with isolated NAFLD and in group 3 with comorbid pathology and obesity. In any case, we can conclude that the level of resistin increases in obese patients along with weight gain, which means that the higher the BMI in obese patients, the more pronounced the effects of resistin on liver function in this category of patients.

\section{Conclusion}

This study essentially shows the presence of significant correlations between resistin and some indicators of the functional state of the liver of the studied patients. The established relationship between the level of resistin and the indicators of the liver functional state suggests that an increase of resistin level may reflect the presence of impaired liver function in patients with NAFLD in combination with DM-2, predicting the progression of NAFLD. In order to detect the disorders of liver function in patients with DM-2, it is recommended to determine the level of resistin in patients with NAFLD, especially when concomitant obesity is present. The higher the BMI in obese patients, the more pronounced the effect of resistin on liver function in this category of patients. 


\section{Declarations}

\section{Statement of Ethics}

The authors have no ethical conflicts to disclosure.

\section{Consent for publication}

All authors give their consent to publication.

Disclosure Statement

The article reflects part of the research work of the department titled "Optimization of diagnosis and treatment of cardiovascular disorders in patients with type 2 diabetes mellitus in terms of combined pathology".

Authors have no potential conflicts of interest to disclosure.

\section{Funding Sources}

There are no external sources of funding

Data Transparency

The data can be requested from the authors.

\section{References}

1. Drapkina O.M., Korneeva O.N. (2016). Continuum of non-alcoholic fatty liver disease: from hepatic steatosis to cardiovascular risk. Ration pharmacother cardiol,12(4), 424-429.

2. Leoni S, Tovoli F, Napoli L, Serio I, Ferri S, Bolondi L. (2018). Current guidelines for the management of non-alcoholic fatty liver disease: A systematic review with comparative analysis. World J Gastroenterol, 24, 3361-73.

3. Younes R, Bugianesi E. (2019). NASH in lean individuals. Semin Liver Dis, 39, 86-95.

4. Kocot J, Dziemidok P, Kielczykowska M, et al. (2017). Adipokine profile in patients with type 2 diabetes depends on degree of obesity. Med Sci Monit, 23, 4995-5004.

5. Lee SH. (2015). Adipokine profiles and metabolic health. Endocrinol Metab (Seoul), 30, 175-6.

6. Ouchi N., J.L. Parker, J.J. Lugus, K. Walsh (2011). Adipokines in inflammation and metabolic disease Nat. Rev. Immunol., 11 (2011), 85-97. https://doi.org/10.1038/nri2921Codoner-Franch P, AlonsoIglesias E. (2015). Resistin: insulin resistance to malignancy. Clin Chim Acta, 438, 46-54.

7. Picu A, Petcu L, Stefan S, et al. (2017). Markers of oxidative stress and antioxidant defense in Romanian patients with type 2 diabetes mellitus and obesity. Molecules, 22:E714.

8. Rajkovic N., Zamaklar M., . Lalic K, Jotic A., Lukic L., Milicic T., Singh S., Stosi L., Lalic N.M. (2014). Relationship between obesity, adipocytokines and inflammatory markers in type 2 diabetes: relevance for cardiovascular risk prevention Int. J. Environ. Res. Pub. Health, 11, 4049-4065. https:// doi.org/10.3390/ijerph110404049

9. Costandi J, Melone M, Zhao A, Rashid S. (2011). Human resistin stimulates hepatic overproduction of atherogenic ApoB-containing lipoprotein particles by enhancing ApoB stability and impairing intracellular insulin signaling. Circ Res., 108, 727-742.

10. Dalamaga M. (2014). Resistin as a biomarker linking obesity and inflammation to cancer: potential clinical perspectives. Biomark Med., 8, №1, 107-118.

11. Huang X, Yang Z. (2016). Resistin's, obesity and insulin resistance: the continuing disconnect between rodents and humans. J Endocrinol Invest, 39, 607-615.

12. Wei Liu, Xianghai Zhou, Yufeng Li, Simin Zhang, Xiaoling Cai, Rui Zhang, Siqian Gong, Xueyao Han, Linong Ji (2020). Serum leptin, resistin, and adiponectin levels in obese and non-obese patients with newly diagnosed type 2 diabetes mellitus. Medicine (Baltimore), .99(6), e19052. doi: 10.1097/ MD.0000000000019052

13. Luo et al., R. Luo, X. Li, R. Jiang, X. Gao, Z. L?, W. Hua (2012). Serum concentrations of resistin and adiponectin and their relationship to insulin resistance in subjects with impaired glucose tolerance J. Int. Med. Res., 40, 621-630. https://doi.org/10.1177/147323001204000224

14. Zaidi and Shirwany, S.I.Z. Zaidi, T.A.K. Shirwany (2015). Relationship of serum resistin with insulin resistance and obesity J. Ayub. Med. Coll. Abbottabad, 27, 552-555.

15. Bertolani C, Sancho-Bru P, Failli P, Bataller R, Aleffi S, DeFranco R, Mazzinghi B, Romagnani P, Milani S, Gines P, et al. (2006) Resistin as an intrahepatic cytokine: overexpression during chronic injury and induction of proinflammatory actions in hepatic stellate cells. Am J Pathol, 169, 2042-2053.

16. Shen, C., Zhao, CY., Wang, W. et al. (2014). The relationship between hepatic resistin overexpression and inflammation in patients with nonalcoholic steatohepatitis. BMC Gastroenterol ,14, 39. https://doi.org/10.1186/1471-230X-14-39

17. Van Haele M., Roskams T. (2017). Hepatic progenitor cells: an update. Gastroenterol Clin North Am, 46, 409-20.

18. Zhuravlova L.V., Ogneva E.V., Vlasenko A.V. (2019). Rol rezistina i gomotsisteina v progressirovanii funktsionalnyih narusheniy pecheni u bolnyih s nealkogolnoy zhirovoy boleznyu pecheni [The role of resistin and homocyctein in the progression of functional liver disorders in patients with non-alcoholic fatty liver disease]. Eksperimentalnaya i klinicheskaya gastroenterologiya, 168, №8, 11-15. 